\title{
Radar signatures beneath a surface topographic lineation near the outlet of Kamb Ice Stream and Engelhardt Ice Ridge, West Antarctica
}

\author{
Kenichi MATSUOKA, ${ }^{1}$ Anthony GADES, ${ }^{1,2}$ Howard CONWAY, ${ }^{1}$ \\ Ginny CATANIA, ${ }^{3}$ Charles F. RAYMOND ${ }^{1}$ \\ ${ }^{1}$ Department of Earth and Space Sciences, University of Washington, Box 351310, Seattle, WA 98195-1310, USA \\ E-mail: matsuoka@ess.washington.edu \\ ${ }^{2}$ Philips Ultrasound, 22100 Bothell Everett Highway, Bothell, WA 98021-8434, USA \\ ${ }^{3}$ Institute of Geophysics, University of Texas, 10100 Burnet Road, Austin, TX 78758-4445, USA
}

\begin{abstract}
Visible and infrared satellite images reveal numerous lineations on the Siple Coast region of West Antarctica. We used $5 \mathrm{MHz}$ ice-penetrating radar to probe the interior and the bed of the ice sheet beneath a lineation at the boundary between Engelhardt Ice Ridge and flat-ice terrain to the south of the Kamb Ice Stream (KIS) outlet. Results show curved reflectors that emerge from the bed beneath $600 \mathrm{~m}$ thick ice. The tops of the reflectors extend about $100 \mathrm{~m}$ into the ice above the bed, where they become almost horizontal. Apparent reflectivity of the horizontal section is about $20 \mathrm{~dB}$ less than that of the bed. We conclude that the likely cause of such strong reflection is sea water that was accreted into basal crevasses when the flat-ice terrain was floating. Internal layers are warped downward just downslope from the basal reflectors. It is thought that the downwarping was caused by localized basal melting in the past. The spatial pattern of downwarping suggests that localized basal melting was stronger on the north side than on the south side of KIS; apparently ice/ocean interactions on the two sides of KIS were different.
\end{abstract}

\section{INTRODUCTION}

Visible and infrared satellite images with $\sim 100 \mathrm{~m}$ resolutions, such as Advanced Very High Resolution Radiometer (AVHRR) and moderate-resolution imaging spectroradiometer (MODIS) images, reveal numerous lineations on the Siple Coast ice streams and the Ross Ice Shelf, West Antarctica (Fig. 1a). The lineations are caused by anomalous surface topography and albedo, which result in brightness variations in terms of illumination angle and satelliteobservation bands. Such lineations have been interpreted to be flow stripes that formed in response to ice sliding over a rough bed (e.g. Hodge and Doppelhammer, 1996; Gudmundsson and others, 1998), and boundaries of current or relict flow regimes such as shear margins of ice streams (Clarke and others, 2000; Jacobel and others, 2000; Catania and others, 2005) and grounding lines (Catania and others, 2005). Characterization of the interior and the bed of the ice sheet beneath such lineations using ice-penetrating radar can help determine their origin, thereby improving understanding of the dynamics and temporal variations of ice streams.

Here we present ice-penetrating radar signatures in the vicinity of a satellite-visible lineation south of Kamb Ice Stream (KIS) in the Ross Sea embayment, West Antarctica (Fig. 1). This lineation delineates Engelhardt Ice Ridge (EIR) from a region of flat-ice terrain, and was hypothesized to be a relict grounding line (Catania and others, 2006a). Hulbe and Fahnestock (2007) proposed that thickness changes on such flat-ice terrains couple the dynamics of adjacent ice streams in the Siple Coast. A similar lightly grounded ice plain has been identified in the mouth of Pine Island Glacier (Corr and others, 2001). We discuss these features in context with those found beneath similar lineations and examine possible origins and glaciological consequences of the radar-detected signatures.

\section{OUTLET OF KAMB ICE STREAM}

KIS stopped flowing fast about 150 years ago (Retzlaff and Bentley, 1993). Both lateral margins at the downstream end of KIS are flanked by flat-ice terrains (Fig. 1). Regional characteristics of ice-penetrating radar signatures have been documented in the northern flat-ice terrain associated with Siple Dome (Jacobel and others, 2000; Catania and others, 2005, 2006b). Near-surface buried crevasses typical of relict ice streams have not been detected in the flat-ice terrains. Radar-detected layers in the terrain are continuous and only slightly warped at the margin to Siple Dome. A ubiquitous feature is a several-kilometers-wide depression in the layer pattern near the margin between the flat-ice terrain and Siple Dome. The downwarping layer pattern observed near the margin can be replicated by an ice-flow model that includes cumulative basal melting of $120-350 \mathrm{~m}$ for up to 300 years based on a melt rate of $\sim 1 \mathrm{~m} \mathrm{a}^{-1}$ (Catania and others, 2006a). They hypothesize that this downwarping pattern is a result of melting at a grounding line. In the flat-ice terrain, numerous basal hyperbolic diffractors are found at sites more than several kilometers from the ridge-terrain margin. The height of the hyperbolic diffractors above the bed is remarkably constant at roughly one-third of the ice thickness. Bed reflectivity in these terrains is much less variable than that found beneath ice streams, and close to that found beneath inter-ice-stream ridges (Catania and others, 2003). Based on these findings, Catania and others (2006a) proposed that the flat-ice terrains represent regions that were floating for a period of time prior to the stagnation of KIS.

In this study, we examine conditions in the vicinity of a satellite-visible lineation that has been hypothesized to be a relict grounding line on the south side of KIS (Catania and others, 2006a). Eight $2 \mathrm{~km}$ long radar profiles were collected to study the characteristics of the ice and the bed in the area 

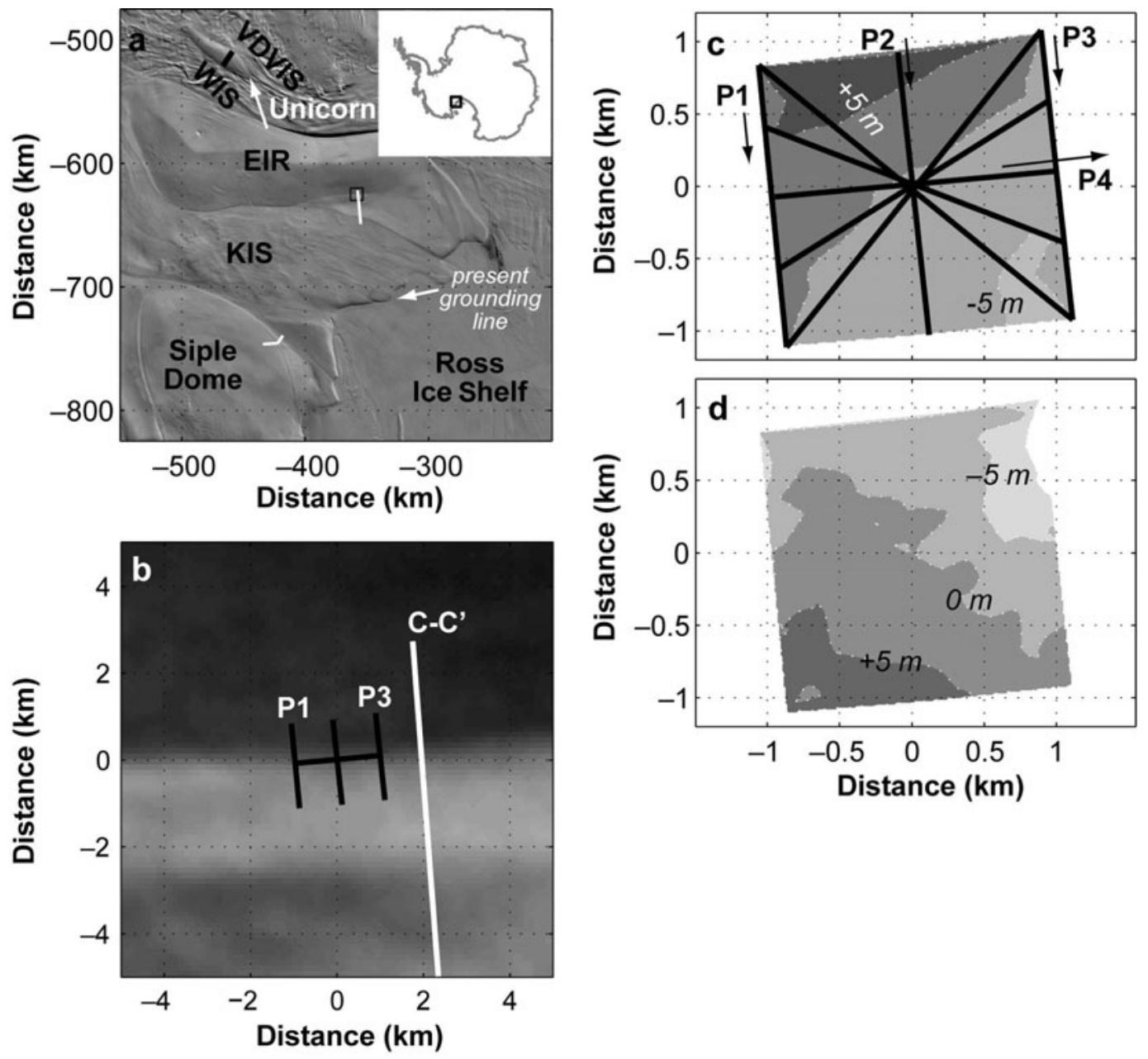

Fig. 1. Study area. (a) MODIS satellite image (125 m resolution) showing numerous satellite-visible lineations around Kamb Ice Stream (KIS) between Siple Dome and Engelhardt Ice Ridge (EIR). Coordinates are polar stereographic, and the inset map shows the location of this panel. The box at the edge of EIR shows the area covered by (b). Two white lines on the north and south sides of KIS outlet show radar profiles that were examined by Catania and others $(2005,2006 a)$. A black line crossing the Unicorn between Whillans Ice Stream (WIS) and Van der Veen Ice Stream (VDVIS) shows the long radar profile made by Clarke and others (2000). (b) Close-up view (10 km by $10 \mathrm{~km})$ of the MODIS image in the vicinity of the study area. Brightness contrasts show that the satellite-visible lineation runs roughly east-west in our local coordinate system parallel to the polar stereographic. Black solid lines shows four of eight radar profiles; P1 and P3 are labeled. The white line shows the profile $C-C^{\prime}$ shown in figure 1 in Catania and others (2006a). (c, d) $2 \mathrm{~km}$ by $2 \mathrm{~km}$ study area. Eight radar profiles are shown with solid lines. Four of them are labeled as P1-P4, which are also shown in (b). Contours show surface (c) and bed (d) elevations relative to the local means.

(Fig. 1b and c): one profile (P4) is nearly parallel to the lineation; three more profiles (P1-P3) were collected perpendicular to P4. A $30 \mathrm{~km}$ long radar profile was also collected (Fig. 1a and b); our study site is in the vicinity of L7 and L8 marked in figure $1 \mathrm{a}$ of Catania and others (2005) and of profile $C-C^{\prime}$ in figure 1 of Catania and others (2006a). We focus attention on this location because of the remarkable basal reflector and downwarped layers evident in profile $\mathrm{C}-\mathrm{C}^{\prime}$.

\section{RADAR SYSTEM AND DATA ANALYSIS}

We used a ground-based impulse radar system with resistively loaded half-wavelength dipole antennas, resonating at $5 \mathrm{MHz}$. The receiver and transmitter were towed inline behind a skidoo; the dipole antennae were also dragged across the surface in line. The separation between the transmitter and receiver was $88 \mathrm{~m}$. We have used the system to characterize variations in echo intensity of the Antarctic ice sheet and temperate glaciers (e.g. Gades and others, 2000; Catania and others, 2003; Matsuoka and others,
2007). The surface elevation relative to the central point of the grid was measured with a pressure transducer, calibrated using a relationship derived from global positioning system (GPS) measurements of surface elevation and coincident pressure measurements on the flank of Siple Dome.

Radar data were collected every $3.1 \mathrm{~m}$; since the platform does not move at a constant speed, the number of stacked waveforms collected during each distance increment varied from 50 to 70 . Variations in white noise associated with the different amounts of stacking were about $0.4 \mathrm{~dB}$. The collected data were bandpass $(5 \pm 2 \mathrm{MHz})$ filtered to increase the signal-to-noise ratio. The radio-wave propagation speed within ice is assumed to be $169 \mathrm{~m} \mathrm{us}^{-1}$, with higher wave speeds in the firn near the surface, based on depth-density measurements from the Siple Coast (Catania and others, 2005). Prominent echoes, including those from the bed, were tracked with a semiautomatic routine that was guided manually to find the largest and smallest voltage levels associated with the layer within a specified depth range. 
(a) Profile P2 (across the lineation)

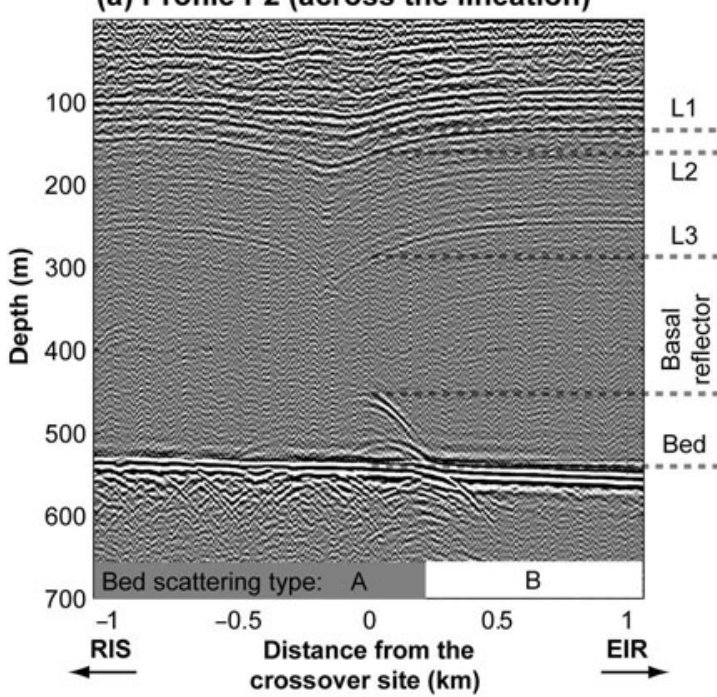

(b) Profile P4 (along the lineation)

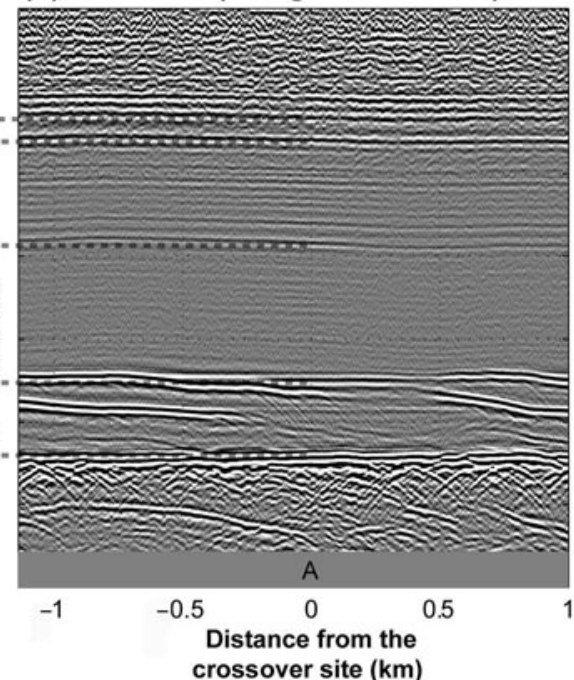

Fig. 2. Radargrams along profiles P2 (a) and P4 (b). Identical grayscale is used for both panels. Bed classification is shown at the bottom of these radargrams. Labels are given to prominent features such as three internal layers (L1, L2 and L3), the most prominent basal reflector and bed. The abscissa is distance measured from the crossover site (local coordinate origin in Fig. 1b-d). Upslope is right (a) and against the paper (b) respectively. Vertically exaggerated by a factor of 3.

Bed-echo intensity can be used as a proxy for bed conditions, but the echo intensity measured by radar is also affected by geometric spreading, attenuation and scattering within the overburden ice, and instrument instability (e.g. Bentley and others, 1998). We calculated the bed-echo intensity as the square of the largest amplitude of the induced voltage associated with the nadir bed reflection (Winebrenner and others, 2003). Similarly, echo intensity is calculated for a distinct reflector near the bed (basal reflector). Spatial variations of scattering and attenuation within the ice are approximated by the internal-echo intensity, which is calculated from the square of the amplitude of induced voltage in the receiving antenna averaged over the ice column (Gades and others, 2000). In order to minimize the effects of temporal variations in noise and the instrumentation, echo intensities have been normalized by the noise intensity calculated from the mean echo intensity over the last $10 \mu$ s in each waveform, i.e. the noise in the waveform after the bed echo.

\section{RESULTS}

\section{Local topography}

Figure 1c and $d$ show variations of surface and bed topography across the study area interpolated from our survey along eight profiles. The surface dips slightly $\left(\sim 0.5^{\circ}\right)$ from EIR towards the ice shelf (Fig. 1c). The bed elevation varies $\sim 25 \mathrm{~m}$ across the area (Fig. 1d), but the directions of surface slopes and bed slopes are different. Catania and others (2005) identified a surface trough of 1-3 m depth at the lineation. However, our study area is slightly upslope from the lineation (Fig. 1b) and the trough is not perceptible in our data.

\section{Shallow and mid-depth layers}

Figure 2a shows a radargram along profile P2 (Fig. 1c), which is roughly perpendicular to the lineation. Continuous layers were detected in the upper half of the ice. Although layers were not detected in the deeper section, we suspect that this was a result of inadequate radar performance rather than layers being physically absent at great depths (known as the echo-free zone (Fujita and others, 1999)). A $30 \mathrm{~km}$ long radar profile (C-C' in Catania and others, 2006a) shows that the internal layers are more-or-less continuous from EIR to the margin between the flat-ice terrain and KIS.

Figure $2 \mathrm{~b}$ shows a radargram along profile $\mathrm{P} 4$, which is nearly parallel to the edge of the lineation (Fig. 1b). Depths of prominent layers along orthogonal profiles P2 and P4 agree well at the crossover site $(\mathrm{km0})$. Three prominent layers, L1-L3 (labeled in Fig. 2), were tracked along three co-parallel profiles P1-P3 (Fig. 3a); layer correspondence is confirmed by tracking these layers along P4. Along all three profiles, the layers beneath the lineation are warped downward. The amplitude of downwarping increases with depth and reaches $\sim 70 \mathrm{~m}$ in the maximum.

\section{Bed characteristics}

Figure $3 \mathrm{~b}$ and $\mathrm{c}$ show, respectively, internal-echo intensity and bed-echo intensity adjusted for the effects $(\sim 0.2 \mathrm{~dB})$ of geometric spreading along profiles P1-P3. The internal-echo intensity along the three profiles varies by $\sim 0.2 \mathrm{~dB}$ during profiling (Fig. 3b), while the range of the bed-echo intensity is approximately $2 \mathrm{~dB}$, an order of magnitude larger than the range of the internal-echo intensity. There is no obvious correlation between the internal-echo intensity and the presence of the basal reflector (see below), probably because the reflector occupies only a small portion of the $\sim 600 \mathrm{~m}$ thick ice over which the internal-echo intensity is averaged. Also, there is no obvious correlation between the internal- and bed-echo intensities, and we conclude that the observed bed-echo intensity is a good proxy of bed conditions with minimal effects from the overlying ice. The bed-echo intensity in the downslope two-thirds of each profile is more variable but its mean is slightly smaller than the upslope one-third (Fig. 3c). 


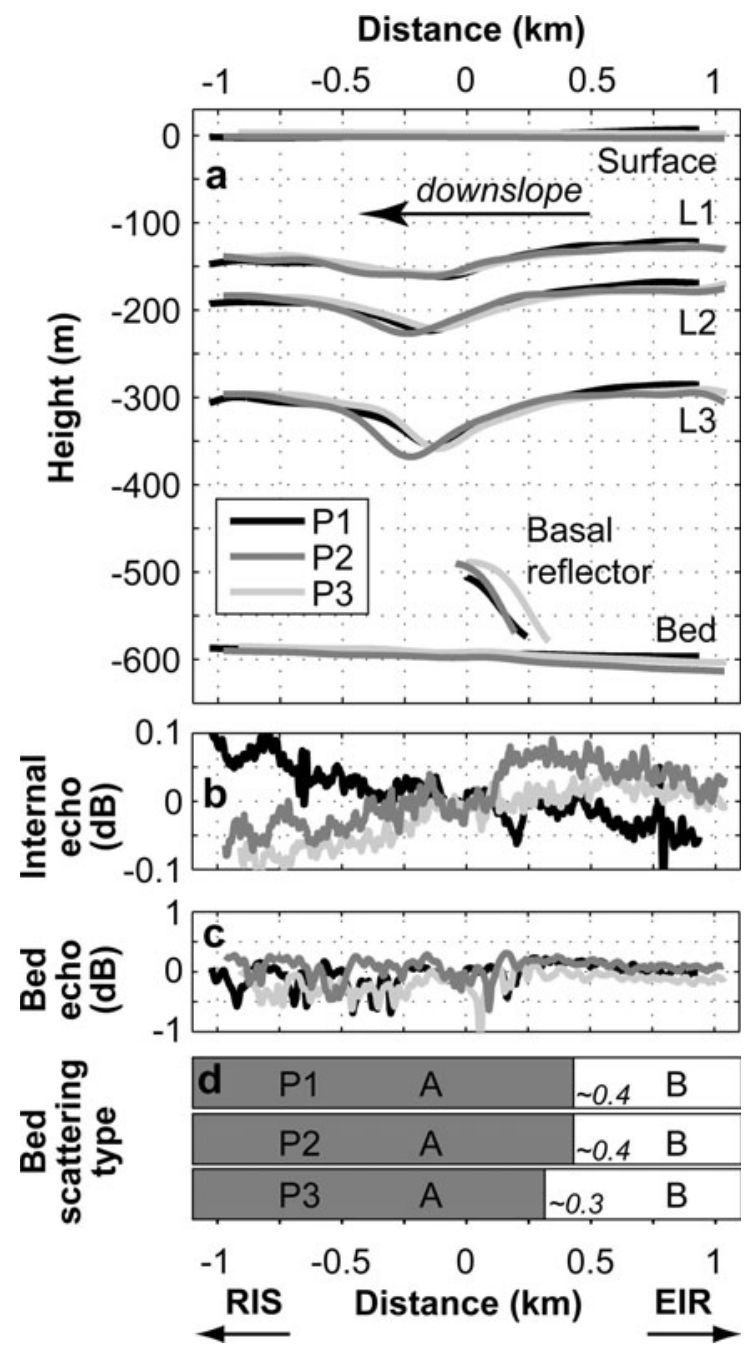

Fig. 3. Radar signatures along three co-parallel profiles P1-P3 (Fig. 1c). (a) Height of surface, layers L1-L3, basal reflector, and bed relative to the local mean level of the surface. Ice flows from right to left. Longitudinal location is referred from the crossover sites of these profiles with the orthogonal profile $\mathrm{P} 4$ which is parallel to the satellite lineation (Fig. 1b). Vertical exaggeration is 3.6. (b, c) Internal (b) and bed (c) echo intensities are normalized with the mean of individual profiles. Note that the ordinate for (b) is ten times finer than that for (c). (d) Bed classification along three profiles. Numbers just right of the boundary give the boundary location in kilometers.

Radargrams shown in Figure 2 suggest that the bed can also be classified by changes in the amount of off-nadir scattering that was recorded after the strong coherent wavelet that we interpret to be the nadir bed reflection. The downslope half to two-thirds of the bed along P2 shows numerous hyperbola-like echoes after the nadir reflection (type A). Profile P4 has this type of bed over the entire profile. In contrast, the upslope one-third of the bed along P2 has much fewer hyperbola-like echoes, but another wavelet (an extra negative peak) after the primary bed echo (type B). The boundary between these two groups occurs slightly upslope of the transition in the bed-echo intensity. Figure $3 d$ shows this classification along P1-P3. We calculated the echo intensity of off-nadir scattering using the same method used for calculating the internal-echo intensity; results do not show a clear boundary in off-nadir echo intensities between types A and B. This is probably

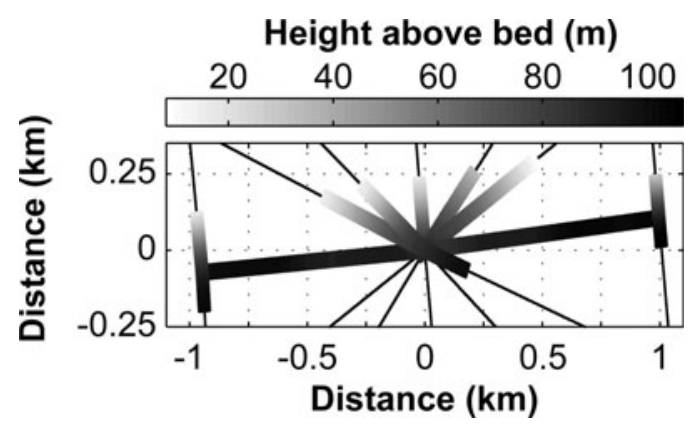

Fig. 4. Height of the basal reflector above the bed along the eight radar profiles shown with a grayscale. Narrower stripes show the radar profiles at which the reflector was not identified. Both ends of the reflector are manually determined. The scales of coordinates are different for better clarity; gridlines are given every $0.25 \mathrm{~km}$ for both axes.

because numerous hyperbolic echoes in A and the extra wavelet in B contribute similarly to the averaged echo intensity, although their characteristics are apparently different. Similar incoherence between features in the radargram and echo intensity was found at Mýrdalsjökull, Iceland (Matsuoka and others, 2007).

\section{Basal reflector}

Radar profiles perpendicular to the lineation reveal curved reflectors that emerge from the bed about $0.5 \mathrm{~km}$ upslope of the stack of downwarping layers (Fig. 2a). The top of the reflector becomes almost flat about $100 \mathrm{~m}$ above the bed and ends within the ice. The remarkable shape is consistent along all three co-parallel profiles P1, P2 and P3 that are each separated by $1 \mathrm{~km}$ (Fig. 3a). However, the asymmetric shape is not consistent with a hyperbola expected from a single target imaged by radio waves. Profile P1 was collected traveling in the upslope direction, while profiles P2 and P3 were collected traveling in the downslope direction; despite the opposite profiling directions, the shape and location of the reflector are similar. Thus, we argue that the physical shape of the basal reflector is essentially that imaged by the radar, and that the echo pattern is not caused by the radio-wave diffraction. Figure 4 shows the height of the basal reflector above the bed derived along all eight profiles. The leading edge of the reflector within the ice was picked manually, but results show that the reflector ends at similar longitudinal locations in all profiles. The results indicate that the reflector is laterally continuous over at least $2 \mathrm{~km}$.

We note that Figure $2 \mathrm{~b}$ shows other less distinct reflectors below the most prominent reflector. One of these merges with the prominent reflector and then separates over the $2 \mathrm{~km}$ profile. Another reflector with more dip is also visible; the basal structure is not as simple as that shown in Figure 3a.

The echo intensities from the most prominent reflector (Fig. 4) and the bed beneath it along profile P4 are shown in Figure 5. The bed-echo intensity (allowing for geometric spreading) varies by about $\pm 0.2 \mathrm{~dB}$. Relative to the bed-echo intensity, the echo intensity of the nearly flat part of the top of the basal reflector ranges between -0.5 and $-2.5 \mathrm{~dB}$. In all three co-parallel profiles perpendicular to the lineation, the bed conditions discussed above change from type B to type $A$ in the vicinity of the basal reflector (Fig. 3d). 


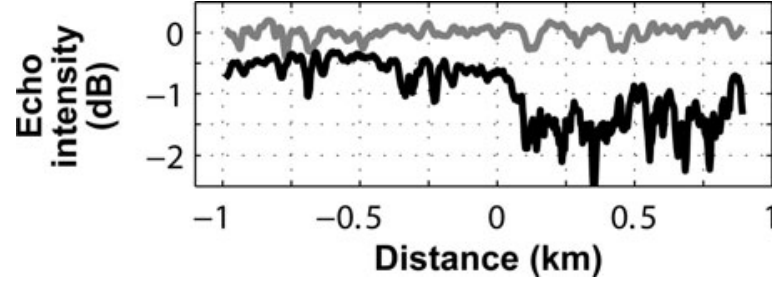

Fig. 5. Echo intensities from the bed (gray) and basal reflector (black) along profile $\mathrm{P} 4$, normalized with the mean of the bed-echo intensity to facilitate a comparison of the echo intensity relative to the bed echo. See text for the compensation of propagation effects during the extra $200 \mathrm{~m}$ travel associated with the bed echo.

\section{RELEVANCE TO RADAR SIGNATURES ASSOCIATED WITH OTHER LINEATIONS}

Radar signatures beneath other lineations (Fig. 1a) have been collected on the north of KIS near Siple Dome (Jacobel and others, 2000; Catania and others, 2005) and across the so-called 'Fishhook' in the Unicorn between Van der Veen and Whillans Ice Streams (Clarke and others, 2000). The former has been interpreted to be a relict grounding line, while the latter has been interpreted to be a relict ice-stream shear margin.

Clarke and others (2000) collected a $13 \mathrm{~km}$ radar profile across the Unicorn and nine shorter profiles that cross the edge of the Fishhook to Whillans Ice Stream. The short profiles were separated by several kilometers. The profiles revealed six basal reflectors along the long radar profile and a basal reflector near the Fishhook in all of the short profiles. In shape they closely resemble the basal reflector that we detected, but they emerge in the upslope direction from the bed (fig. 7 in Clarke and others, 2000), which is opposite to the direction of our reflectors (Fig. 3a). Four of the Clarke reflectors extend through $\sim 5 \%(50 \mathrm{~m})$ of the total ice thickness $(\sim 1000 \mathrm{~m})$. The others extend through 10\% $(100 \mathrm{~m})$ and $23 \%(230 \mathrm{~m})$ of the ice thickness. The height of the reflectors that we mapped is $17 \%(170 \mathrm{~m})$ of the ice thickness (Fig. 3a), which is similar to the range of heights of the Clarke reflectors.

Clarke and others (2000) suggested that their reflector could be caused by entrained morainal debris, a bottom crevasse or partial melt. Hot-water drilling above one of the reflectors met with abnormal resistance about $56 \mathrm{~m}$ above the bed, and the drill tip was freshly scratched, suggesting that it had encountered debris. Clarke and others (2000) concluded that the debris-rich ice contributed to cause the reflector. It is unlikely that they are open crevasses since the observed radar echo does not match well with typical echo patterns (hyperbolae) from open crevasses (Peters and others, 2007).

Jacobel and others (2000) and Catania and others (2005) detected a basal reflector slightly downslope of the layer depression at the margin between Siple Dome and the flatice terrain north of KIS. In our study on the south side of KIS, the basal reflector is located about $0.4 \mathrm{~km}$ upslope from the downwarping layers (Fig. 2a). The orientation of the reflector is the same as ours, but, again, it is opposite to that of the Clarke reflectors (fig. 7 in Clarke and others, 2000). Bed-type transitions are less distinct on the north side, but they appear to alternate from type $B$ to type $A$ and then type $B$ again over a $12 \mathrm{~km}$ long profile (fig. 4 in Catania and others, 2005). At the Siple Dome margin, the bed-type transition occurs about
$2 \mathrm{~km}$ downslope from the basal reflector, while it occurs $\sim 300 \mathrm{~m}$ upslope from the reflector at the EIR margin.

Catania and others (2006a) examined the pattern of downwarping layering at the margin between Siple Dome and the flat-ice terrain north of KIS. The downwarping extends over several kilometers, and the largest depression is about $200 \mathrm{~m}$. In contrast, the downwarping on the south side of KIS extends over $0.5 \mathrm{~km}$ and depressions are up to $70 \mathrm{~m}$. On the north side, the layers drop sharply on the upslope side and then return to their original depths more gradually. Such asymmetry in the layer pattern is not apparent on the south side. Catania and others (2006a) used an ice-flow model to investigate possible causes of the layer pattern including: (1) anomalous surface mass balance; (2) changes from sticky to slippery bed conditions; and (3) localized basal melt. Results showed that localized basal melting was needed to match the observed layer pattern. They also showed that a symmetric (Gaussian) spatial pattern of basal melt could result in an asymmetric layer pattern.

In summary, although the ice and bed beneath the lineations exhibit apparently similar structures (i.e. layer patterns, basal reflectors and alternating bed types), the relative location and structural properties (i.e. orientation with respect to surface slope, depression and reflector height and symmetry) of these radar signatures differ from site to site. On the Unicorn, the Clarke reflector is oriented upslope, while it is oriented downslope on both sides of KIS. Previous studies identified the basal reflector along single or separate profiles. Here, we have shown clearly that the basal reflector on the south side of KIS is continuous over at least $2 \mathrm{~km}$ (Fig. 4).

\section{ORIGIN OF THE RADAR SIGNATURES}

The downwarping layer pattern (Fig. 3a) has similar features to those studied by Catania and others (2006a), who showed that the layer pattern implies localized basal melting. We infer that the layer pattern on the south side of KIS is also a result of basal melting, but with less cumulative melt. Variations in bed-echo intensity in the vicinity of the downwarping layers are small (Fig. 3c in this paper and also fig. 4 in Catania and others, 2003), suggesting that the melt occurred in the past and the bed is currently frozen.

The laterally continuous and coherent structure of the basal reflector and the presence of the lineation imply that the location of this margin remained fixed for an extended period of time. The absence of bedrock bumps and the low bed slope (Fig. 1d) suggest that its location is not controlled by the local bed topography. The horizontal position of the maximum layer depression is remarkably constant through the depth of the ice sheet (Fig. 3a). We might expect that cumulative ice flow after the formation of the pattern would result in a downwarping layer pattern that is tilted because flow of isothermal ice at half of the ice thickness is $\sim 6 \%$ smaller than the surface velocity (Paterson, 1994). Assuming a surface velocity of $0.9 \mathrm{~m} \mathrm{a}^{-1}$, the same as that measured by Jacobel and others (2000) in the flat-ice terrain on the north side of KIS, we expect that the near-surface layers would shift laterally relative to mid-depth layers by about $5 \mathrm{~m}(100 \mathrm{a})^{-1}$. If localized basal melting stopped 350 years ago (Catania and others, 2006a), the shift would be about $20 \mathrm{~m}$. If basal melting stopped 670 years ago, with a timing of a sudden shear-margin jump at the northern side of KIS (Hulbe and Fahnestock, 2007), the shift would be about 
$34 \mathrm{~m}$. Shifts of these magnitudes are difficult to resolve with our data; it is not surprising that the observed layer pattern does not show evidence of tilting.

Catania and others (2006a) suggested that the flat-ice terrains were (at least nearly) floating in the past. Following this hypothesis, we investigated the possibility that the reflectors are accreted sea water. One possibility is that the reflectors were originally bottom crevasses filled with sea water; multiple reflectors (Fig. 2) could be caused by complicated basal crevasse structures or multiple-crevasse opening/closing events at different times. Lower ice temperature near the tops of the basal crevasses would provide a more favorable environment for freeze-on than the bottom of the ice sheet. As the flat-ice terrain became grounded, the crevasses would start to close, resulting in thin layers of accreted ice between meteoric ice. Another possibility is that marine water accreted in a basal cavity so that there is currently $100 \mathrm{~m}$ of accreted ice. However, such thick impurity-rich ice at temperatures close to the melting point would attenuate the radio waves (MacGregor and others, 2007), causing a marked decrease in the observed bed-echo intensity. There is no evidence for such large attenuation in the lower section of the ice sheet (Fig. 3c), so we argue against a thick layer of accreted ice. Echo intensity of the reflector is $0.5-2 \mathrm{~dB}$ smaller than the bed-echo intensity adjusted for geometric spreading (Fig. 5). Typical Fresnel reflectivity of a dry bed is $-10 \mathrm{~dB}$ (Peters and others, 2005). Radio-wave attenuation during the $200 \mathrm{~m}$ round trip between the reflector and bed is about $6 \mathrm{~dB}$ for pure ice at $-5^{\circ} \mathrm{C}$ (MacGregor and others, 2007); the apparent reflectivity of the basal reflector is about $-18 \mathrm{~dB}$. If the ice is warmer and/or includes soluble ions, the attenuation is larger and the apparent reflectivity smaller. Although ice temperature and impurity content beneath the reflector are unknown, attenuation there does not appear to be unusual, and we suspect that the ice is clean rather than lossy marine accreted ice. Therefore, we estimate that the apparent reflectivity of the basal reflector is about $-20 \mathrm{~dB}$. The Fresnel reflectivity of the basal reflector can be estimated using dielectric models, although some caution is needed when comparing Fresnel reflectivity with the apparent reflectivity calculated above because the basal reflector is not an infinite plane. However, it can provide clues about possible origins of the basal reflector. The permittivity of debris-rich ice can be estimated with a dielectric mixture model (Looyenga, 1965). Permittivity of minerals ranges between 5 and 8 (e.g. Keller, 1966). An apparent reflectivity of -30 to $-20 \mathrm{~dB}$ would require the volume fraction of minerals in the ice to be about $30 \%$ (Paren, 1981). This is much higher than concentrations typically observed in basal ice (e.g. Cuffey, 1999; lizuka and others, 2001). Accreted marine ice is less conductive than sea ice, but still much more conductive than meteoric ice; chemical analysis of four sections of marine accreted ice from the Ronne Ice Shelf showed highfrequency conductivity ranging from 150 to $200 \mu \mathrm{s} \mathrm{m}^{-1}$ at $-22^{\circ} \mathrm{C}$, which is $60-400$ times smaller than that of sea ice (Moore and others, 1994). Ice conductivity increases rapidly with temperature (MacGregor and others, 2007); the conductivity of marine accreted ice from the Ronne Ice Shelf would be $150 \%$ higher at $-10^{\circ} \mathrm{C}$ and $175 \%$ higher at $-5^{\circ} \mathrm{C}$, resulting in a Fresnel reflectivity of -20 to $-34 \mathrm{~dB}$ at temperatures between $-5^{\circ} \mathrm{C}$ and $-10^{\circ} \mathrm{C}$. We conclude that accreted marine ice is most likely the cause of the basal reflector observed in this study.
Our analysis of bed-echo intensity and bed type (A and B) shows small changes in bed conditions near the basal reflector. The bed-echo intensity is slightly smaller and more variable downslope of the basal reflector. Small changes in bed roughness could cause such reduction of the specular reflectivity (Peters and others, 2005). Reduction of basal reflectivity is a function of a root-mean-square deviation $S$ from the average bed plane relative to the radio-wave wavelength $\lambda(\sim 34 \mathrm{~m}$ at $5 \mathrm{MHz}$ in ice). The observed reduction of bed-echo intensity $(\sim 1 \mathrm{~dB})$ could occur if $S / \lambda$ changes from 0 to 0.02 , or from 0.05 to 0.06 , which corresponds to $S$ changing by $0.35-0.7 \mathrm{~m}$ in the vicinity of the basal reflector. Such change in bed roughness is also consistent with the observation that off-nadir scattering increases across the transition.

Additional data are needed to establish conclusively the origin and cause of the basal reflector, but our preferred hypothesis is that it is caused by a thin layer of marine accreted ice that formed in open basal crevasses when the flat-ice terrain was afloat. The basal reflector and downwarping layers occur at a location where the basal conditions change. Present-day ice flow is slow $\left(<1 \mathrm{~m} \mathrm{a}^{-1}\right)$ and it is thought that the northern flat-ice terrain became grounded 350 years ago (Catania and others, 2006a) to 670 years ago (Hulbe and Fahnestock, 2007). Therefore, we speculate that both basal melting and crevasse opening/ accretion occurred nearly simultaneously in the vicinity of the grounding zone.

Comparison of radar-detected signatures on the south side of KIS with those on the north side indicates: (1) an order-of-magnitude difference in the dimensions of layer depression; (2) opposite lateral locations between the layer depressions and basal reflectors; and (3) different variations in bed conditions. These differences indicate that interactions between ocean and ice were likely different on the north and south sides of KIS. Hulbe and Fahnestock (2007) suggested that flat-ice terrains in the lower reaches of the ice streams play a key role in coupling the dynamics of adjacent ice streams and that variations in flow of Whillans Ice Stream exert strong control on the flow of KIS. If correct, we infer that the dynamic connections of KIS with Bindschadler Ice Stream to the north and Whillans Ice Stream to the south have been different. Bathymetric data in this area are limited, which hampers detail modeling of ocean/icecoupled dynamics. More radar data characterizing ice interior and bed are also necessary to fully establish the evolution of glaciological conditions in the region and the chronology of events. In this study we show that unusual radar-detected signatures found in previous work are locally coherent. These signatures can be used to explore the evolution of regional glaciological conditions.

\section{CONCLUSIONS}

Ice-interior and bed structures beneath the satellite-visible lineation at the margin of EIR were examined using $5 \mathrm{MHz}$ ice-penetrating radar. We detected downwarping internal layers from shallow to mid-depths, and basal reflectors that extend up to $100 \mathrm{~m}$ above the bed. Our survey shows that the basal reflectors are laterally continuous along the lineation over at least $2 \mathrm{~km}$, suggesting regionally coherent glaciological conditions when these radar-detected structures formed. Similar structures were found in previous studies near a relict shear margin between Van der Veen and 
Whillans Ice Streams (Clarke and others, 2000), and another near a relict grounding line between Siple Dome and flat-ice terrain to the north of KIS (Catania and others, 2006a). Our results support the hypothesis that the satellite-visible lineation between EIR and flat-ice terrain south of KIS is a relict grounding line (Catania and others, 2006a). However, the different chronologies of events on either side of KIS and the order-of-magnitude differences in melting suggest that ice/ ocean interactions on the northern and southern sides of KIS were different. Our results are consistent with estimates by others for the timings for the grounding of the flat-ice terrains (Catania and others, 2006a; Hulbe and Fahnestock, 2007).

\section{ACKNOWLEDGEMENTS}

This work was supported by US National Science Foundation grants OPP-9909518 and ANT-0338151. MODIS satellite imagery was distributed by the US National Snow and Ice Data Center. We thank T. Scambos and M. Conway for assistance in the field. We also thank the scientific editor O. Eisen and reviewers R. Bingham and M. Luthi for constructive comments that helped improve the manuscript.

\section{REFERENCES}

Bentley, C.R., N. Lord and C. Liu. 1998. Radar reflections reveal a wet bed beneath stagnant Ice Stream $C$ and a frozen bed beneath ridge BC, West Antarctica. J. Glaciol., 44(146), 149-156.

Catania, G.A., H.B. Conway, A.M. Gades, C.F. Raymond and H. Engelhardt. 2003. Bed reflectivity beneath inactive ice streams in West Antarctica. Ann. Glaciol., 36, 287-291.

Catania, G.A., H. Conway, C.F. Raymond and T.A. Scambos. 2005. Surface morphology and internal layer stratigraphy in the downstream end of Kamb Ice Stream, West Antarctica. J. Glaciol., 51(174), 423-431

Catania, G.A., H. Conway, C.F. Raymond and T.A. Scambos. 2006a. Evidence for floatation or near floatation in the mouth of Kamb Ice Stream, West Antarctica, prior to stagnation. J. Geophys. Res., 111(F1), F01005. (10.1029/2005JF000355.)

Catania, G.A., T.A. Scambos, H. Conway and C.F. Raymond. 2006b. Sequential stagnation of Kamb Ice Stream, West Antarctica. Geophys. Res. Lett., 33(14), L14502. (10.1029/2006GL026430.)

Clarke, T.S., C. Liu, N.E. Lord and C.R. Bentley. 2000. Evidence for a recently abandoned shear margin adjacent to Ice Stream B2, Antarctica, from ice-penetrating radar measurements. J. Geophys. Res., 105(B6), 13,409-13,422.

Corr, H.F.J., C.S.M. Doake, A. Jenkins and D.G. Vaughan. 2001. Investigations of an "ice plain" in the mouth of Pine Island Glacier, Antarctica. J. Glaciol., 47(156), 51-57.

Cuffey, K.M. 1999. Glaciological investigations beneath an active polar glacier. (PhD thesis, University of Washington.)

Fujita, S. and 6 others. 1999. Nature of radio-echo layering in the Antarctic ice sheet detected by a two-frequency experiment. J. Geophys. Res., 104(B6), 13,013-13,024.
Gades, A.M., C.F. Raymond, H. Conway and R.W. Jacobel. 2000. Bed properties of Siple Dome and adjacent ice streams, West Antarctica, inferred from radio-echo sounding measurements. J. Glaciol., 46(152), 88-94.

Gudmundsson, G.H., C.F. Raymond and R. Bindschadler. 1998. The origin and longevity of flow stripes on Antarctic ice streams. Ann. Glaciol., 27, 145-152.

Hodge, S.M. and S.K. Doppelhammer. 1996. Satellite imagery of the onset of streaming flow of Ice Streams C and D, West Antarctica. J. Geophys. Res., 101(C3), 6669-6677.

Hulbe, C. and M. Fahnestock. 2007. Century-scale discharge stagnation and reactivation of the Ross ice streams, West Antarctica. J. Geophys. Res., 112(F3), F03S27. (10.1029/ 2006JF000603.

lizuka, Y., H. Satake, T. Shiraiwa and R. Naruse. 2001. Formation processes of basal ice at Hamna Glacier, Sôya Coast, East Antarctica, inferred by detailed co-isotopic analyses. J. Glaciol., 47(157), 223-231.

Jacobel, R.W., T.A. Scambos, N.A. Nereson and C.F. Raymond. 2000. Changes in the margin of Ice Stream C, Antarctica. J. Glaciol., 46(152), 102-110.

Keller, G.V. 1966. Electrical properties of rocks and minerals. In Clark, S.P., Jr, ed. Handbook of physical constants. New York, Geological Society of America, 553-577.

Looyenga, H. 1965. Dielectric constant of heterogeneous mixtures. Physica, 31(3), 401-406.

MacGregor, J.A., D.P. Winebrenner, H. Conway, K. Matsuoka, P.A. Mayewski and G.D. Clow 2007. Modeling englacial radar attenuation at Siple Dome, West Antarctica, using ice chemistry and temperature data. J. Geophys. Res., 112(F3), F03008. (10.1029/2006JF000717.)

Matsuoka, K., Th. Thorsteinsson, H. Björnsson and E.D. Waddington. 2007. Anisotropic radio-wave scattering from englacial water regimes, Mýrdalsjökull, Iceland. J. Glaciol., 53(182), 473-478.

Moore, J.C., A.P. Reid and J. Kipfstuhl. 1994. Microstructure and electrical properties of marine ice and its relationship to meteoric ice and sea ice. J. Geophys. Res., 99(C3), 5171-5180.

Paren, J.G. 1981. Correspondence. Reflection coefficient at a dielectric interface. J. Glaciol., 27(95), 203-204.

Paterson, W.S.B. 1994. The physics of glaciers. Third edition. Oxford, etc., Elsevier.

Peters, M.E., D.D. Blankenship and D.L. Morse. 2005. Analysis techniques for coherent airborne radar sounding: application to West Antarctic ice streams. J. Geophys. Res., 110(B6), B06303. (10.1029/2004JB003222.)

Peters, M.E., D.D. Blankenship, D.E. Smith, J.W. Holt and S.D. Kempf. 2007. The distribution and classification of bottom crevasses from radar sounding of a large tabular iceberg. IEEE Geosci. Remote Sens. Lett., 4(1), 142-146.

Retzlaff, R. and C.R. Bentley. 1993. Timing of stagnation of Ice Stream C, West Antarctica, from short-pulse radar studies of buried surface crevasses. J. Glaciol., 39(133), 553-561.

Winebrenner, D.P., B.E. Smith, G.A. Catania, H.B. Conway and C.F. Raymond. 2003. Radio-frequency attenuation beneath Siple Dome, West Antarctica, from wide-angle and profiling radar observations. Ann. Glaciol., 37, 226-232. 